\title{
Evaluation of a Training Program in a Local Hotel in Jordan
}

\author{
Nader Saadeh ${ }^{1}$ \\ ${ }^{1}$ Institution: University of Northampton, England \\ Correspondence: Nader Saadeh, Independent Researcher, School of Business and Law, The University of \\ Northampton, Northampton, England. \\ Received: February 27, 2020 \\ Accepted: August 3, 2020 \\ Online Published: August 12, 2020 \\ doi:10.5539/ibr.v13n9p1 \\ URL: https://doi.org/10.5539/ibr.v13n9p1
}

\begin{abstract}
The main focus of this paper is on a training program for telephone skills that was conducted at the end of January 2019 in a local hotel in Jordan. Depending on the philosophy of this study, choosing a qualitative investigation is appropriate because it examines the informers' position of behaviours and experiences being studied (Dawson, 2002). The research suggests that a limited amount of training program evaluation has a limited impact on performance improvements. A case-study approach was conducted in this evaluation. Besides, the data used for this study is primary in nature, as it reflects the participants' observations (Saunders, Lewis, and Thornhill, 2007) and is based on the subjective qualitative research approach (Greener, 2008). The data collected were based on interviews taken from ten employees and the human resources manager (HRM) of the hotel. According to HRM view, it has been found that the telephone skills training program did have an impact of change mainly on the front office employees.

Furthermore, it has been found that training has a sustainable effect and was a motivation by itself for the employees. However, learning processes which were addressed in literature were not considered in this program. Therefore, limited impact on performance and culture was identified. This evaluation attempt is an introduction for future research associated with training programs within the local hotel industry in Jordan.
\end{abstract}

Keywords: change, culture, evaluation, impact on employees, Jordan, local hotels, performance, training program

\section{Introduction}

In recent years, a growing need for evaluating the effectiveness of training programs in organisations has been identified (Adams and Waddle, 2002; Lingham, Richley, and Rezania, 2006; Barrett, 2016; Fox, Grimm, and Caldeira, 2017). Jordan local hotels are a vital area for investigating this phenomenon since growing numbers of those hotels are emerging in the Jordanian tourism market (Jordan statistical yearbook, 2018). In contrast, service quality is declining according to practitioners (Batarseh, 2018 and Saadeh, 2018); that is why it is essential to assess training programs in this sector. Moreover, the neglect of owners and managers to evaluate training programs has been identified, and according to professionals, it is associated with management and leadership styles (Batarseh, 2018 and Saadeh, 2018).

This evaluation research aims to partially contribute to the understanding of the local-hotel training role and its impact on the employees through a training program evaluation in a local Jordanian hotel. It is also based on the assumption that a limited amount of training program evaluation has a limited impact on performance improvements.

\subsection{Definitions}

In this sense, a program evaluation is "the determination of the value of a product, a process, or a program" (Barrett, 2016) and, in terms of its document goal attainment justification, it is to describe the outcomes in a completed program (Barrett, 2016). In their seminal study (Rossi, Lipsay, and Freeman, 2003) defined a program evaluation as a "social science activity directed at collecting, analysing, interpreting, and communicating information about the workings and effectiveness of social programs". However, in program effectiveness exploration, a researcher needs to "understand change over time and identify the underlying factors that contributed to change" in the performance of the organisation or the department in which the training is done (Fox et al., 2017). Therefore, these questions would be asked in change-impact evaluation: "how did the intervention (training program) work?" and "why did the intervention cause the impact?" (Fox et al., 2017). 
Special consideration should be taken to understand the difference between a research project and a research "evaluation" project, through asking this question: In what sense evaluation is different from research? Barrett (2016) answers that it is in its "focus", in the "questions being asked," and in its "goals". Thus, evaluation research focuses on a specific program, asks questions that are specific to this program and aims to improve, justify or assess the needs of the program. In contrast, a research project focuses on theory, asks general questions, and aims to increase knowledge (Barrett, 2016). This study emphasises on a training program assessment to improve its impact on employees performance. Therefore, it is considered as a "research evaluation project".

\subsection{Methodology}

In this case, a case study could be one of the appropriate methods which can be carried out to evaluate the professional practice that enhances decision making (Fox et al., 2017). In other words, a case study tends to answer the how and why questions and will work in an environment where the researcher would not manipulate the behaviour of those involved in the evaluation study (Yin, 2009; Denzin and Lincoln, 2011). Those were the conditions that existed in the hotel's environment being evaluated. Therefore, in this evaluation research, the case-study method will be conducted in order to assess the training program.

In this paper, the main focus is on a training program for telephone skills that was conducted at the end of January 2019 in a local hotel in Jordan. This program focused on professional service use with internal and external callers while providing a suitable greeting and farewell to them. It also focused on the use of the telephone service effectively, transfer and place a call on hold, and on taking a written message.

It is vital to understand that this case study is an attempt to evaluate the impact of change through looking backwards from the point in time of an interview (Fox et al., 2017). A case study in a focus group method will be done to reach those findings owing to the nature of the program, which was held for three groups of employees in three different departments of the hotel. Consequently, an investigation will be carried out on how the trainees and the human resources manager construct the meaning of the outcomes of the training program. Besides, it is an attempt to identify the stakeholders' perception of this social-professional reality; that is the resulted performance of the trainees after conducting the training program, which is subjectively constructed through their interaction (Bryman and Bell, 2011; Denzin and Lincoln, 2011 ).

\subsection{Evaluation Question}

Therefore the reason that developed the evaluation questions is to detect whether the program influenced the employees or not. Thus the study aims to answer those evaluation questions as follows:

How did the telephone-skills training program cause (or did not) an impact of change in the workplace, on the trainees' culture and performance who attended the program? Why did it influence change (or not) in trainees' perception and conduct?

\section{Literature Review}

Randolph (2009) explains that the faulty collection of literature leads to derail a dissertation. Hence if the literature review is flawed, the rest of the study may be viewed as defective. In respect of this evaluation study, the focal point is in gathering information from the literature that discusses the critical aspects of the evaluation question: "how and why a training program causes an impact of change on employees' culture and performance".

\subsection{Culture}

Evaluations of training programs are becoming increasingly essential to manage intellectual capital of business organisations (Adams and Waddle, 2002). Assessments of those programs have been apparent in helping to improve the outcomes of performance within which is the context of this study (Lingham et al., 2006; Newby and Bramley, 2008; Helitzer, Yoon, Wallerstein, and Garcia-Velarde, 2009).

Adams and Waddle (2002) argue that evaluation is the process of attempting to assess the total value of training. However, Kissack and Callahan (2009) suggest that including a culture analysis during the organisational analysis portion of the needs assessment is vital. Likewise, it has been found that ineffective training evaluation is directly associated with the organisational culture (Lewis and Thornhill, 1994). Lewis and Thornhill (1994) argued that an attempt must be first considered to understand the corporate culture and the organisation attitudes towards evaluation. Practitioners in the local-hotel industry in Jordan (Batarseh, 2018 and Saadeh, 2018), have reported this issue about owners and managers who neglect the learning process to their human capital.

In this context, this study aims to examine how a training program would affect cultural change, as an embedded element, that reflects in organisational performance change. However, not all the mentioned assessment-elements 
will apply to this study because it is beyond its scope.

\subsection{Double-Loop Learning}

In contrast, Rowe (1996) differs from the above authors in suggesting that evaluation requires researchers to be engaged in "double-loop learning". This process indicates that while evaluating, one has to return to the objectives of the program themselves and inquire whether they still apply or not. He concludes that with "double-loop learning" a researcher investigates the uncertainties which are associated with the training and development process and evaluate the aims and objectives of the program itself. On the contrary, (Blackman et al., 2004) argue that there are "potential weaknesses in the double-loop learning for reliable knowledge creation because of the ongoing testing of the original problem and the new solution". However, the paper suffers from a poorly developed theory as numerous researchers showed the significance of double-loop learning on organisational innovation and performance, the transformation of the firm, and its impact on a higher level of collaborative know-how (García-Morales et al., 2009; Sisaye and Birnberg, 2010; Simonin, 2017). The double-loop learning process consists of questioning the objectives and methods of which are included in the program's design. Therefore, this evaluation will observe whether an application of this model exists during the process of designing the training program. Nonetheless, a non-detection of this model in practice will show a gap in developing learning processes in training programs in this hotel.

\subsection{Components of Learning Process}

A great deal of previous research has focused on learning in the organisation as a crucial role of impact on performance change. In fact, many studies focused on the significance of the learning process of the trainees and its effects on corporate performance as a result. Garavan's (1997) evaluation study on a mid-size hotel of a social skills training program has found that there is a linkage between the power of behaviour change (learning) and service effectiveness. The evaluation purpose was to determine the gap between planning and reality and make the recommendations to the hotel. The findings showed that the response was influential during the training itself, but with less impact on the long run. This study seemed to ignore issues of changing employees' attitudes, which have a sustainable influence on performance. However, according to (Garcia-Santillán, Moreno, Carlos, and Zamudio, 2012), three components influence the learning process of individuals when trying to change their attitudes: the cognitive aspect (how people think), the behavioural perspective (how people act), and the affective aspect (how people feel). Hence in evaluating a training and development program, an evaluator has to explore how this program is designed and does it have an improving impact on employees' attitudes?

Another study (Popper, 2000) described the role of leaders' styles in determining values that facilitate effective learning. The method of leaders was structural and systematic in collecting, analysing, storing, disseminating and using information that is relevant to the performance of the firm. The findings of the study indicated a link between the role of leaders and effective learning (Popper, 2000). This component of learning process demonstrates a vital role in performance.

Similarly, (Sessa et al., 2018) investigated the multiteam learning systems. The multiteam systems are "an organisational form that consists of multiple teams in a fluid of semi-permanent network" (Sessa et al., 2018). They found that when individuals and component teams are ready to learn along with the environmental support for learning, the multiteam systems learn continuously. Hence, these systems provide reflection, invention, and transformation in preparation for future missions. In this respect, this evaluation study will observe if any of these methods were existent in the training program design of this hotel.

\subsection{Emotion Work}

Further studies focused on a different aspect, which influences the learning process of the trainees. Mirchandani (2012) and Dick and Bernstorff (2009) focused on emotion work (EW). Mirchandani (2012) argued that (EW) has to be included in the program's content since it has an impact on enhancing the communication skills of "call centre agents" as a result of his study. This aspect of learning is a vehicle through which employees learn to make sense of their place in social, economic and cross-national environments (Mirchandani, 2012). What the paper meant by (EW) is "to refer to the relational work which many people do as part of their jobs". It is related to the concept of taking ownership of the "call" and letting clients acknowledge that they are in the right hands (Mirchandani, 2012). Training in this respect could enhance the social interaction with the customers, which in turn change employees culture in the workplace and boost performance. In this respect, it is vital for an evaluation study to concentrate on this facet in a program, whether it exists or not. Alternatively, Dick and Bernstorff (2009), who investigated emotional dissonance ${ }^{1}$ (ED) in call centre work, showed that (ED) was

${ }^{1}$ It is the lack of agreement or harmony between people or things. 
associated with lower work motivation. They also found that positive affectivity correlated negatively with (ED). In comparison, negative affectivity correlated positively with customer aggression.

Consequently, emotion work has to be emphasised in the workplace as it has a vast influence on the overall employee performance. Although this aspect was not expected to be found in the training design of this hotel, it was suggested, in the recommendation section, to have it included in future training programs. It will be determined in prospective research evaluation, through identifying relational work among employees that reflects emotional work and includes it in the training program.

\subsection{Cultural Diversity}

Mirchandani (2012) stresses the idea of communicating with diverse cultures in the workplace. It is relevant that an evaluation study, in a hotel environment, focuses on the existence of varying content with different cultural possibilities, which trains employees how to deal with different cultures. For example, social interaction, language, verbal contacts with customers and many other interconnections are vital components in a hospitality environment. Moreover, a recent study ( Anjorin, Jansari, and Nazir, 2018) stressed the value of cultural diversity in the workplace. Although this thesis had some limitations in its scope, the findings showed the significance of this facet in increasing productivity of the staff and achieving positive outcomes. This topic was addressed during the interviews to explore the extent of its understanding (appendix 4). It was also included in the recommendations section.

\section{Methodology}

It is crucial to discuss the design of this evaluation report in the current section. The methods and methodologies which formulate the model, explain what the research is, and how is it done, allowing the reader to evaluate the reliability and validity of the study (McCombes, 2019).

\subsection{Philosophy}

The research philosophy adopted in a study carries significant assumptions about the way a researcher views the world. Those assumptions will bear the methodology, methods, approach, strategies, choices, time horizons and techniques chosen as part of the study (Greener, 2008; Saunders et al., 2007). Figure 3.1 illustrates the research philosophy by the onion shape ${ }^{2}$.

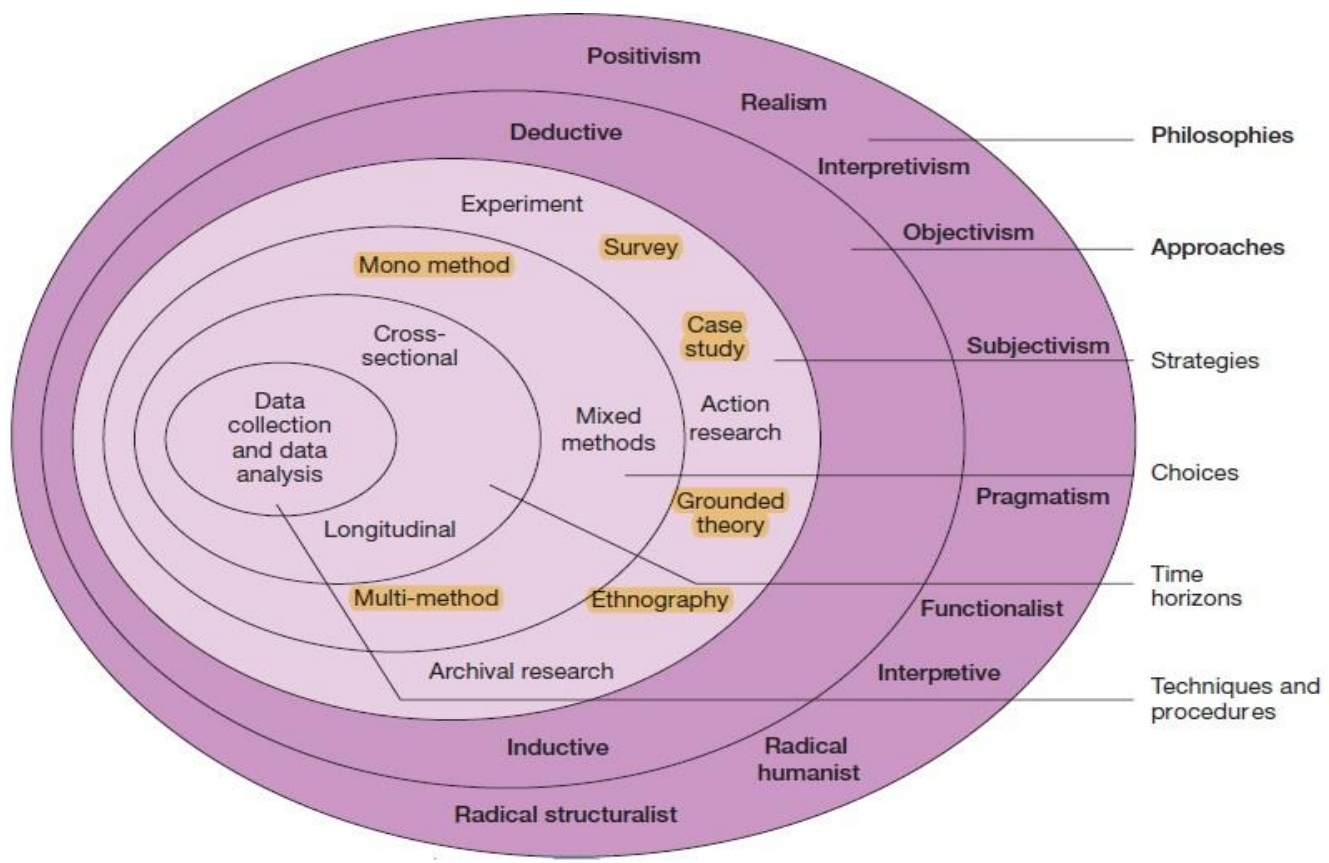

Figure 3.1. The research onion shape - Source: Saunders, Lewis and Thornhill, 2007

\footnotetext{
${ }^{2}$ Methodologies represent strategies in the diagram (Dawson, 2002; Bryman and Bell, 2011).
} 
Moreover, (Dawson, 2002) states that when a researcher thinks about the methodology, he or she needs to think about qualitative and quantitative research. Alternatively, there is a difference between qualitative and quantitative analysis. Qualitative research explores attitudes behaviours and experiences where they tend to reflect an interpretive position and constructivist stand. In contrast, quantitative research generates statistics, where they tend to reflect a positivist position and objective stand (Dawson, 2002; Bryman and Bell, 2011). Qualitative research uses methods such as interviews, or focus groups, whereas quantitative research uses techniques such as questionnaires or structured interviews (Dawson, 2002).

This evaluation study is exploratory. It is an attempt to understand how the management and the staff in this hotel interpret the results of the training program. Bryman and Bell (2011) explain that if the research problem was formulated to stress the tenuousness ${ }^{3}$ of the firm and its culture as objective categories, it is likely that the research would actively involve the participants in reality construction. Therefore, this evaluation study takes the interpretive constructivist stand because it tries to interpret how and why the employees understand the impact of the training program, and how they construct their reality through the results of the program.

\subsection{Methods}

The data used for this study is primary in nature, as it reflects the participants' observations (Saunders et al., 2007). Its use is based on the subjective qualitative research approach (Greener, 2008). The data collected were based on interviews taken from ten employees and the human resources manager (HRM) of the hotel. In-depth interviews were addressed to the departmental groups in a set of prompt semi-structured open-ended questions. In-depth interviews were chosen because they attempt to get in-depth opinions from the participants (Dawson, 2002). Semi-structured questions were selected because they are "a list of questions on fairly specific topics to be covered, often called the schedule (Appendix 5); however, the interviewee has a lot of other ways in how to reply. Consequently, questions may not follow the outline set on the schedule" (Bryman and Bell, 2011). An mp3 audio machine will record the interviews.

Each group formulates each department, which is why three focus groups will be chosen for this study (see appendix 1). The same questions will be asked to the human resources manager. The study will investigate the how and why questions and will try to understand how did this training program affect the trainees' performance in the workplace and why did they interpret their performance the way they are explaining it (cultural facet). In this sense, the outcomes would be a social construct in which the researcher is trying to grasp the subjective meaning of social action (Bryman and Bell, 2011; P. Eriksson and A.Kovalainen, 2016).

The case study is the approach that "facilitates the exploration of a phenomenon within its context using a variety of data sources" (Angelelli and Baer, 2016). Therefore, this evaluation research will use the case-study method using the training documents and multiple interviews outcomes within the hotel, to explore this phenomenon within its context (Yin, 2009). Moreover, this study aims to investigate employees' performance through the lenses of the involved actors and requires prior categorisation of the occurrence (Angelelli and Baer, 2016). Accordingly, a case study will be conducted on a telephone skills training program for specific work-groups within the hotel's workplace environment.

Why focus groups in this case study evaluation?

Focus groups are bound to the use of qualitative data. They offer the researcher the opportunity to study the collective understanding of a group towards a phenomenon (Bryman and Bell, 2011). This is also suitable to this evaluation paper.

This study will also denote a detailed schedule (see appendix 5) and will use transcribed recordings to analyse the themes that will emerge. The critical point of using focus groups is the appropriateness of the generation of new ideas formed in a social context within the groups (Breen, 2006).

Hence, the use of homogenous groups within one department in each recording will be done to achieve this purpose. The interviews in the focus groups will generate qualitative data which will be recorded and transcribed; then, a thematic analysis will be done across the meetings. Thematic analysis is a highly inductive procedure, where it is used to collect and analyse qualitative data simultaneously (Dawson, 2002). It involves classifying the data into meaningful categories, derived from the theoretical framework and must fit what the research has revealed (Saunders et al., 2007). It is also a method of identifying, analysing and reporting common ideas within a set of qualitative data (Clarke and Braun, 2013; Anderson, 2007). It recognises the themes within the data, where emerging patterns become codes and categories for investigation (Fereday and Muir-Cochrane, 2006).

3 That is: Weak or thin in consistency. 
Therefore, this approach was selected in this study to analyse the data, while coding and categorisation were done manually (shown in appendix 4). Besides, a search for the main emerging themes and patterns was done, then analysed systematically through defining relationships, compare and contrast and finding gaps; a process that involves reflecting on whether the data tell a convincing story or not.

Moreover, thematic analysis is a flexible process and can be used to analyse data from focus groups and interviews (Clarke and Braun, 2013). Therefore, the thematic analysis approach was selected to extrapolate the main themes of the transcribed interviews and analyse them accordingly. Four interviews were conducted: three for the departmental parties, and one for the human recourses manager. Same questions will be used for all groups. The focus-group interview schedule (Breen, 2006) is demonstrated in Appendix 5. The documents of the hotel about the program are presented in appendices 1 and 2. Analysis of the focus-group data includes ${ }^{4}$ the most important themes, quotes, and unexpected findings (Breen, 2006).

\subsection{Sample}

A purposive sampling technique was chosen because of the nature of this evaluation research. Richie, Lewis, and Elam (2013) argue that in a criterion based on purposive sampling, sample units are chosen because they have particular features that enable a detailed examination of the phenomenon being studied. Accordingly, this paper focused on three groups who had specific features for the study. It concentrated on evaluating a telephone skills training program which is done in a four stars hotel situated in the Dead Sea area of Jordan. The human resources manager conducted the program for two days on January 25, 2019, and the 26th. The duration of the program was one hour for each day and was intended for all departments. Three departments attended the program as follows ${ }^{5}$ (HRM, 2019, see appendix 1):

- $\quad$ Front office (three employees - one female)

- $\quad$ Housekeeping (four employees - all males)

- $\quad$ Service area - food (four employees - all males)

None of those departments attended the program:

- $\quad$ Accounting

- Security

Hence a total of eleven employees participated in the program, who resemble the population studied (Fox et al., 2017).

The sample was limited because the evaluation has been done for this particular hotel. However, this evaluation research could be an insight for future assessments within the Jordanian local-hotel industry.

\subsection{Ethical Considerations}

Ethics is about relating to moral choices and influencing decisions and behaviours (Greener, 2008). In this study, relevant ethical considerations were taken while collecting the data. For example, following the moral code of the hotel, full information provision about the purpose of the evaluation, and gaining the consent of the participants without causing any harm to them are vital actions that were considered in the study (Greener, 2008; Saunders et al., 2007). Furthermore, the evaluation regarded the respect of the informers in keeping their rights to confidentiality and anonymity as a significant act in its course. It also maintained objectivity and avoided embarrassment stress and discomfort while conducting the research (Greener, 2008; Saunders et al., 2007). These steps were taken while conducting this evaluation research.

\subsection{Procedures}

A timely plan (see appendix 3) was prepared in a Gantt chart presentation to manage this evaluation-study project. This study focused on in-depth interviews that started with the human resources manager (HRM) and then the other three focus groups that consisted of the employees in the mentioned departments. After the first interview was done, which was conducted on February 26, 2019, with the HRM, the researcher called for the first focus group, which was available at the time. The department of housekeeping was the available one, according to the hotel schedule. However, one of the employee-trainees was in the hospital, and his partner who happened to be another trainee accompanied him. It was not easy for the researcher to postpone the interview because of the time limitations, the remoteness of the hotel's location and the difficulties in appointing interviews.

${ }^{4}$ More detailed description about the analysis of the data is demonstrated in the findings section.

5 (that had particular features in the context of the study) 
Therefore it was agreed upon resuming the second interview while adding one of the front office trainees with the two housekeeping trainees. The third and the forth interviews went as scheduled. Accordingly, the total interviewed employees were nine employees ( $81.8 \%$ of the population), in addition to the human resources manager.

The human resources manager was addressed in English. At the same time, most of the employees in the focus groups were communicated in Arabic, and the transcription was translated into English for the thematic analysis purposes.

\section{Findings}

After transcribing the interviews, a thematic analysis was done to extrapolate the emerging themes from the answers (see appendix 4).

The themes mainly come from interviewees. The categorisation process involved organising and coding the data to develop the main ideas, to capture the richness of the facts and interpret them (Fereday and Muir-Cochrane, 2006). Consequently, the main themes were presented first, resembling main categories while subcategories, which were shown below each leading group, resembled the subthemes extracted from the qualitative data.

\subsection{First Interview (HRM)}

According to the methods used and explained above, five categories emerged from the data of the first interview. O'Connor and Gibson (2003) emphasise that maintaining reliability ${ }^{6}$ and validity ${ }^{7}$ in the data analysis, and the findings are crucial. They also encourage the qualitative analyst to start thinking inside the box, then outside the box. That is when analysing the data, to keep in mind the original questions that are meant to be answered. Then, to look at other ideas and themes that have emerged from the data (surprises), (O'Connor and Gibson, 2003b, p.66). These aspects were considered in the process of analysis. Thus the main categories were as follows:

- New skills and knowledge.

- Impact - sub-themes.

- Development within other departments needs more time to clarify.

- The program's procedures were feasible and appropriate. (Feasible)

- The program is motivation by itself. (Motivation)

- Improvement lasted after one month from the date of the program. (Sustainable)

- Improvement was mainly within the front office employees. (Improvement-FO)

- The duration was convenient. (Duration)

- The content was enough. (Content)

- Repetition enhances improvement. (Repetition)

It was noticed that advanced learning procedures mentioned in the literature review were not addressed in the training program, for example, double-loop learning, emotion work and cultural diversity materials, which could develop a training strategy. Another topic was embedded in the conversation of the HRM regarding the cultural issues related to learning among employees. However, he did not show any concern about changing it. Furthermore, the HRM did not indicate any clear understanding of the multiteam learning system, the impact of learning components on attitude nor the role of leaders in learning. Jugder (2016, p.4) argues that a conceptual framework has to be formed, reflecting the connection of the main ideas to identify meaning. Therefore, figure 4.1 demonstrates the relationship between the different themes extrapolated from the data in a conceptual framework. The same procedure of analysis will be repeated in other interviews.

According to HRM view, it has been found that the telephone skills training program did have an impact of change mainly on the front office employees. Furthermore, it had a sustainable effect and was a motivation by itself for the employees. The HRM was content with the program and did not show a need for further training, although he admitted that 'repetition improves effectiveness'. These findings demonstrate that this program did cause a positive change in performance. However, learning processes which were addressed in literature were not considered in this program. Therefore, limited impact on performance and culture was identified.

${ }^{6}$ Consistency in interviewing, transcribing and findings (O’Connor and Gibson, 2003, p.72).

${ }^{7}$ Accuracy of the method (O’Connor and Gibson, 2003, p.72). 


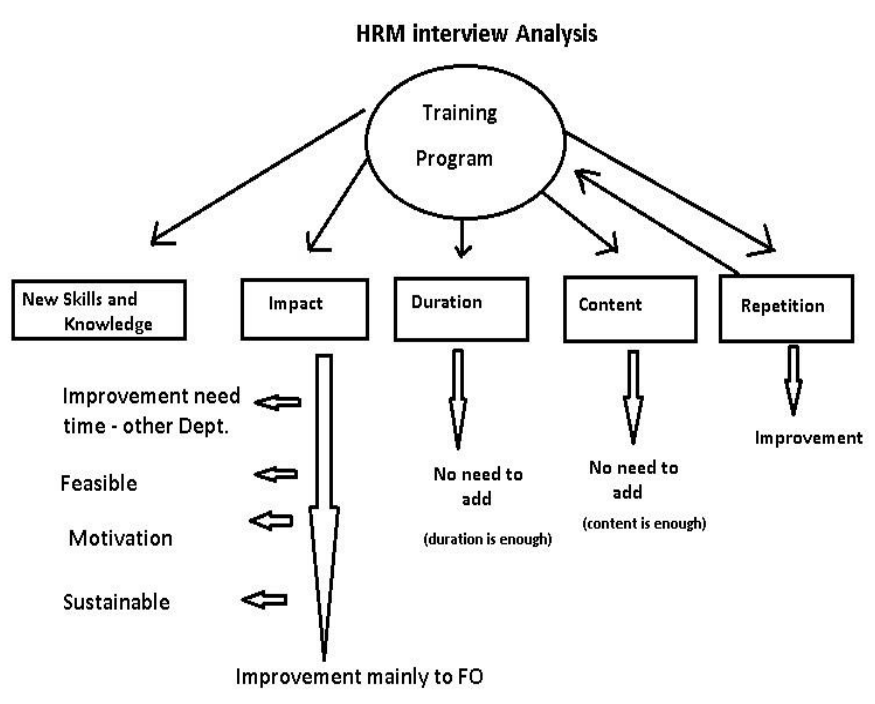

Figure 4.1. HRM Interview Analysis - Source: Author

\subsection{Housekeeping (HK) and Front Office (FO) Interviews}

The main categories and sub-themes that emerged from housekeeping (HK) and front office (OF) departments' interviews were as follows:

- New skills and knowledge - subthemes

- Connecting with guests HK

- Sales skills HK-OF

- Problem-solving HK

- Gentle wordings with guests HK

- Use of telephone skills FO

- Impact - sub-themes

○ Review and refresh existing skills HK-FO

- Communication with customers HK-FO

$\circ$ Enhance remembering to what is learned HK

- Organising guests' demands HK

- Addition of knowledge FO

- Duration - sub-themes

○ Not enough time for questions HK-FO

- Content - sub-themes
$\circ$ Enough HK
- Clear HK
- Need more content to enhance experience FO
- Motivation HK-FO
○ Repetition leads to improvement HK-FO
- Need for more training HK-FO

Figure 4.2 demonstrates the relationship between the different themes emerged from the data. 


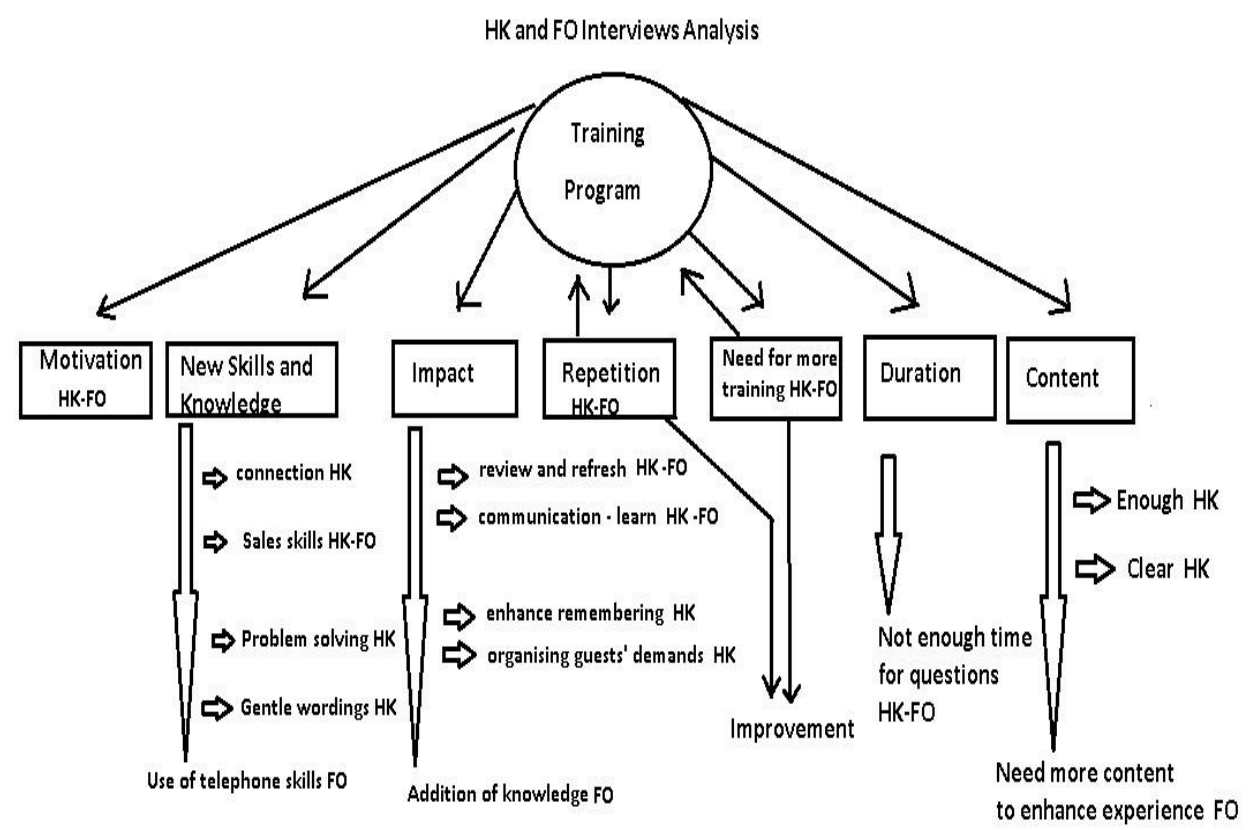

Figure 4.2. HK and FO interviews Analysis - Source: Author

From the HK and FO departments' interviews, it has been found that the training program created motivation, a need for repetition and more training. However, this tendency has not been detected within the HRM interview. Therefore, this HRM's attitude reflects the negligence of management in enhancing skills and learning, while employees expressed a necessity to improve. Furthermore, the program did have an impact of change in creating new skills and knowledge and reviewing and refreshing existing ones. It also had an effect on guest-communication and gentle wordings with customers. However, some employees expressed their need for more extended programs, and more content to improve their experience. These findings mirror the impact of change on the employee's culture in the workplace and their performance. Yet, this program was limited in its effect. While some employees questioned parts of the program design, which reflected a "double-loop learning" $\operatorname{method}^{8}$, other procedures of advanced learning, which were discussed in the literature review were not demonstrated in the program design.

This result reveals the gap in improving the training from literature and other experiences and the lack of designing better programs that have a better impact on culture and performance.

Besides, the FO department reported the need for training on the operator console, the fire alarm system and the handicapped needs. This necessity was verbalised and written in the manuscripts (appendix 4).

\subsection{Service Area - food (SA) Interview}

The main categories and sub-themes that emerged from (SA) department interview were as follows:

- New skills and knowledge

$\circ$ Adding new ones to new employees.

- Review and refresh existing ones.

○ Helps to remember.

- Impact

- Improvement in using gentle wordings.

- Improvement in communicating with guests.

${ }^{8}$ As employees expressed the need for more training, repetition and duration (presented in appendix 4). 
- Improvement in communicating with other departments.

- Existing employees may train new ones.

- Enhance teamwork

- Enhance co-operation among departments.

- Motivation by itself. The program is motivating and leads to performance improvement.

- Duration

$\circ$ Enough

- Content

$\circ$ Enough - covered all needed points

- Clear

- Need extended training material in the future.

○ Need training on departmental relations.

- Repetition of the program leads to improvement.

- Local guests issues (hinders performance).

Figure 4.3 demonstrates the relationship between the different themes emerged from the data.

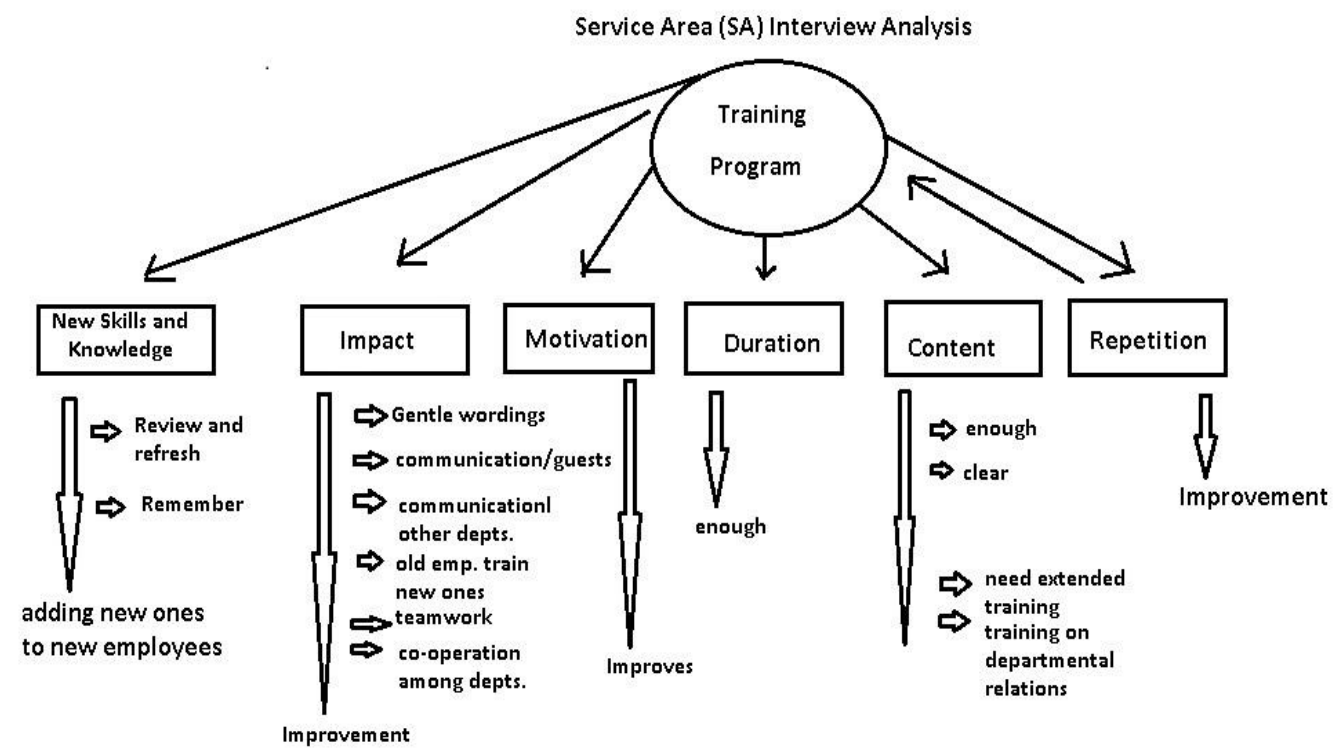

Figure 4.3. SA interview Analysis - Source: Author

The last interview revealed similar results comparing with other departments. The SA employees revealed that the program created motivation, a need for repetition and more training. The training added new skills to existing staff and new employees, and it had an impact of change on their performance. For example, the team gained skills in guest communication, communication among departments and they had gentle wordings towards the guests.

However, they expressed their need for extended training materials and repetition of the program as these aspects improve their performance and experience. Besides, this interview reflected the limitation of the program since it did not demonstrate any of the procedures discussed in the literature review section that boost performance and change the organisation culture.

Furthermore, as this evaluation progressed in the department of the food service area, it was found that the participants suggested that there is an element in the culture of local guests that hinders training programs to develop their performance. For instance, they mentioned that local guests are "headache". They try to exploit 
tourist packages and have an attitude. They always complain of something, bargain in prices and argue intentionally to obtain more service. Therefore, behaviour coming from local guests regress their performance and involves cultural issues. The staff also requested more training to be done on departmental relations and co-operation and asked for the addition of departmental telephone numbers cards in each room. These requests are mentioned in the original manuscripts (appendix 4).

Consequently, in the following section, recommendations were considered to enhance the cultural change process, which can improve performance.

\section{Recommendations}

This evaluation study has shown the implementation of the objectives of the training program. However, it revealed limited progress in cultural change and the impact of change on performance. Therefore the following recommendations are suggested to the human resources manager and the management of the hotel. This study encourages the stakeholders to act upon the issues that hinder any future training from having a change in the organisational culture that would reflect on improving employees' performance.

In the beginning, this evaluation study suggests the repetition of any existing or new training program periodically which proposition is confirmed by Gist, Bavetta, and Stevens (1990). This process could be arranged with the employees according to their schedules and needs. Moreover, this study recommends extending the content of future programs consisting of methods and procedures that develop performance and change the staff's culture in the workplace. For example "emotion work", "cultural diversity", "double-loop learning", "multiteam learning systems", and "role of leaders in learning" (Mirchandani, 2012; Dick and Bernstorff, 2009; Anjorin et al., 2018; Rowe, 1996; García-Morales, Verdú-Jover, and Javier Lloréns, 2009; Sisaye and Birnberg, 2010; Simonin, 2017; Sessa et al., 2018; Popper, 2000) are methods worth to be investigated from the hotel's management. Those procedures could be found in literature and training program designs in related institutions. It also encourages the stakeholders to research in literature and specialised institutions about methods that deal with employees' cultural and attitude change (Adams and Waddle, 2002; (Lingham et al., 2006; Newby and Bramley, 2008; Helitzer et al., 2009; Lewis and Thornhill, 1994; Garavan, 1997; Garcia-Santillan et al, 2012). Those topics are recommended to be included in future training programs since they have a significant impact on the hotel's performance.

This evaluation also suggests adopting extended training material in the telephone skills program concerning the way how to handle complaints and emotional responses such as the program in (KSL Consulting LTD, 2018). It also recommends conducting training and development programs related to improving the team spirit and departmental co-operation.

The study also recommends providing information cards that show the departmental phone numbers in every room and suggests providing teaching sessions on the operator console to the FO staff, preparing and teaching for handicapped needs and training the FO employees on the fire alarm system.

The evaluation results encourage assessing employees' cultural change (Rousseau and Cooke, 1988) and performance (Lusthaus, Adrien, Anderson, Carden, and Montalván, 2002) in the workplace using professional assessment tools. These tools could be found in related training institutions. Recommendations are also made for the management to associate the performance improvement and cultural change in the workplace of any employee with bonuses, promotions and salary raising to boost motivation (Green and Heywood, 2007). It is also recommended to extend the duration of the training to provide time for feedback and employee questions.

According to the foodservice area's (SA) comments, this evaluation recommends to limit the food packages to the local guests and promote those packages to non-local ones.

Finally, the researcher recommends putting this slogan on every training program "TRAINING IS PERFORMANCE VALUE".

\section{Conclusion}

Training and development programs are crucial in the local hotel sector in Jordan due to their effect on employees' cultural change and performance in the workplace. This study has unveiled the importance of the evaluation process of training programs, which are rationale and systematic, through using the scientific approach. It revealed a change on performance; however, developed performance and change in employees' culture were limited. It is essential to note that this evaluation study has shown that a limited amount of training program evaluation has a limited impact on performance improvements. More future case-study evaluations on training and development programs are required in this sector, due to the need of detecting the level of performance in this field. Moreover, further evaluations are needed to identify low performance related to culture. 
Hence, once they are achieved, it is necessary to communicate those studies' findings with the stakeholders to make an impact of change out of those interventions.

This study was limited to an evaluation of a training project in a local hotel in Jordan. Further assessments are required to be done in the future on other training programs and in other local hotels. It is crucial to detect whether training has an effect on culture change and performance in local hotels and to what extent.

\section{References}

Adams, D., \& Waddle, C. (2002). Evaluating The Return From Management Development Programs: Individual Returns Versus Organisational Benefits. International Journal of Contemporary Hospitality Management, ProQuest. Emerald, pp.14-20. https://doi.org/10.1108/09596110210415079

Anderson, R. (2007). Thematic Content Analysis (TCA): Descriptive Presentation of Qualitative Data Using Microsoft Word, Sofia University. Retrieved from https://s3.amazonaws.com/academia.edu.documents/36098984/Thematic_Content_Analysis_manuscript.pd f?response-content-disposition=inline $\% 3 \mathrm{~B} \%$ 20filename $\% 3$ DTHEMATIC_CONTENT_ANALYSIS_on_Mi crosoft_W.pdf\&X-Amz-Algorithm=AWS4-HMAC-SHA256\&X-Amz-Credential=AKIAIWOWYYGZ2Y5 3UL3A\%2F20190822\%2Fus-east-1\%2Fs3\%2Faws4_request\&X-Amz-Date $=20190822 \mathrm{~T} 154010 \mathrm{Z} \& \mathrm{X}-\mathrm{Amz}$ -Expires=3600\&X-Amz-SignedHeaders=host \&X-AmzSignature=181634c909d1e0efe4fc3df5b857c8a6818 $847 f 1$ cc540c6bca586c15dc970e22.

Angelelli, C., \& Baer, J. (2016). Research Translation and Interpreting. Chapter 14. https://doi.org/10.4324/9781315707280

London and New York. Routledge, Taylor and Francis group. Retrieved from https://books.google.jo/books?hl $=$ en\&lr=\&id=GPcsCgAAQBAJ\&oi=fnd \&pg=PP1\&dq=Research+Translation+and+Interpreting + Angelelli, $+\mathrm{C} .,+$ and + Baer, $+\mathrm{J} . \& o t s=$ nCYJZs71LH\&sig=Icsplqoyp2vsYgSog8eoatpUCnY\&redir_esc=y\#v=onepage \&q $=$ Research $\% 20$ Translation $\% 20$ and $\% 20$ Interpreting $\% 20$ Angelelli $\% 2 \mathrm{C} \% 20 \mathrm{C} . \% 2 \mathrm{C} \% 20$ and $\% 20 \mathrm{Baer} \% 2 \mathrm{C} \% 2$ $0 \mathrm{~J} . \& \mathrm{f}=$ false

Anjorin, R. A., Jansari, A., \& Nazir, I. (2018). 'Managing Cultural Diversity at Workplace Title: Managing Cultural Diversity at Workplace', (May), pp. 1-56. Retrieved from https://www.divaportal.org/smash/get/diva 2:1217 258/FULLTEXT01.pdf

Barrett, N. (2016). Program Evaluation: A Step-by-Step Guide [online] revised edition. Sunnycrest Press, Kindle Edition. Retrieved from https://www.amazon.com/Program-Evaluation-Step-Step-Revised/dp/0988394898

Blackman, D., Connelly, J., \& Henderson, S. (2004). Does double-loop learning create reliable knowledge?. The Learning Organization, 11(1), 11-27. https://doi.org/10.1108/09696470410515706

Breen, L. R. (2006). A practical Guide to Focus-Group Research [online]. Routledge Taylor and Francis Group. Journal of Geography in Higher Education, 30(3), 463-475. https://doi.org/10.1080/03098260600927575

Bryman, A., \& Bell, E. (2011). Business Research Methods (3rd ed.). England. Oxford University Press.

Clarke, V., \& Braun, V. (2013). Teaching Thematic Analysis: Overcoming Challenges and Developing Strategies for Effective Learning. Department of Psychology, The University of Auckland. New Zealand. Retrieved from

http://eprints.uwe.ac.uk/21155/3/Teaching\%20thematic\%20analysis\%20Research\%20Repository\%20versio n.pdf

Dawson, C. (2002). Practical Research Methods: A user-friendly guide to mastering research techniques and projects (1st ed.). Oxford UK: howTobooks. Retrieved from http://www.modares.ac.ir/uploads/Agr.Oth.Lib.21.pdf

Denzin, N. K., \& Lincoln, Y. S. (2011). The Sage Handbook of Qualitative Research (4th ed.). USA. Sage Publications Inc.

Dick, R. V., \&Bernstorff, C. V. (2009). Emotional Dissonance In Call Centre Work.

Eriksson, P., \& Kovalainen, A. (2016). Qualitative Methods In Business Research (2nd ed.). Los Angeles USA: Sage. Retrieved from https://books.google.jo/books?hl=en\&lr=\&id=YvICwAAQBAJ\&oi=fnd\&pg $=\mathrm{PP} 1 \& \mathrm{dq}=$ philosophy+behind+business+research\&ots=MLyoEt7CXT\&sig=ppnZ70gR-MOTJ51HfBZh-sf EsyU\&redir_esc=y\#v=onepage $\& \mathrm{q}=$ philosophy behind business research $\& \mathrm{f}=$ true

Fereday, J., \& Muir-Cochrane, E. (2006). Demonstrating Rigor Using Thematic Analysis: A Hybrid Approach Of Inductive And Deductive Coding And Theme Development. International Journal of Qualitative Methods, 
5(1), 80-92. https://doi.org/10.1177/160940690600500107

Fox, C., Grimm, R., \& Caldeira, R. (2017). An Introduction To Evaluation. SAGE Publications. Kindle Edition.

Garavan, T. (1997). Interpersonal Skills Training For Quality Service Interaction. Industrial and Commercial Training. Emeraldinsight, 29(3), 70-77. https://doi.org/10.1108/00197859710165056

García-Morales, V. J., Verdú-Jover, A. J., \& Javier Lloréns, F. (2009). The Influence Of CEO Perceptions On The Level Of Organisational Learning: Single-Loop And Double-Loop Learning. International Journal of Manpower, 30(6), 567-590. https://doi.org/10.1108/01437720910988984

Garcia-Santillán, Moreno, A., Carlos, E., \& Zamudio, J. (2012). Cognitive, Affective And Behavioral Components That Explain Attitude Toward Statistics. Journal of Mathematics Research, 4(5). https://doi.org/10.5539/jmr.v4n5p8

Gist, M. E., Bavetta, A. G., \& Stevens, C. K. (1990). Transfer Training Method: Its Influence On Skill Generalization, Skill Repetition, And Performance Level. Willey Online Library. Personal Psychology. https://doi.org/10.1111/j.1744-6570.1990.tb02394.x

Green, C., \& Heywood J. (2007). Does Performance Pay Increase Job Satisfaction? Economica, 75, 71-728. https://doi.org/10.1111/j.1468-0335.2007.00649.x

Greener, S. (2008). Business Research Methods [online]. Free Books at BookBoon.com. Ventus Publishing ApS. Retrieved from http://gent.uab.cat/diego_prior/sites/gent.uab.cat.diego_prior/files/02_e_01_introduction-to research-methods.pdf

Helitzer, D., Yoon, S., Wallerstein, N., \& Garcia-Velarde, L. (2009). The Role Of Process Evaluation In The Training Of Facilitators For An Adolescent Health Education Program. Journal of School Health. Wiley Online Library. https://doi.org/10.1111/j.1746-1561.2000.tb06460.x

Jordan Statistical Year book. (2018). Retrieved from http://dosweb.dos.gov.jo/products/jordan-statistical-yearbook-2018/

Jugder, N. (2016). The Thematic Analysis Of Interview Data: An Approach Used To Examine The Influence Of The Market On A Curricular Provision In Mongolian Higher Education Institutions. The University of Leeds. Retrieved from https://pdfs.semanticscholar.org/2e0a/746b717fa49b6f4a48a462ee47e602204de9.pdf?_ga=2.198382188.29 9386060.1566740649-567466198.1566740649

Kissack, H., \& Callahan, J. (2009). The Reciprocal Influence Of Organizational Culture And Training And Development Programs: Building The Case For A Culture Analysis Within Program Planning. Journal of European Industrial Training, 34(4), 366-380. https://doi.org/10.1108/03090591011039090

KSL Consulting LTD (2018) Telephone Skills Course. Retrieved from https://www.ksl-training.co.uk/in-company-training/communication-skills-courses/telephone-skills/

Lewis, P., \& Thornhill, A. (1994). The Evaluation Training: An Organizational Culture Approach. Journal of European Industrial Training, 18(8), 25-32. https://doi.org/10.1108/03090599410068042

Lingham, T., Richley, B., \& Rezania, D. (2006). An Evaluation System For Training Programs: A Case Study Using A Four-Phase Approach. Career Development International, 11(4), 334-351. https://doi.org/10.1108/13620430610672540

Lusthaus, C., Adrien M., Anderson, G. Carden, F., \& Montalván, G. P. (2002). Organizational Assessment: A Framework For Improving Performance. International Development Research Centre/Inter-American Development Bank. National Library of Canada cataloguing in publication data. Retrieved from https://pdfs.semanticscholar.org/2d3f/a6acd4bd329a91ff93cdc7624605ed4977cf.pdf

Mirchandani, K. (2012). Learning Racial Hierarchies: Communication Skills Training In Transitional Customer Service Work. Journal of Workplace Learning. Emeraldinsight, 24(5), 338-350. R https://doi.org/10.1108/13665621211239877

Newby, A. C., \& Bramley, P. (2008). 'The Evaluation Of Training Part II. Journal Of European Industrial Training, 8(7), 17-21. https://doi.org/10.1108/eb002185

O'Connor, H., \& Gibson, N. (2003). A Step By Step Guide To Qualitative Data Analysis. Pimatiziwin: A Journal of Aboriginal and Indigenous Community Health, 1, 63-90. Retrieved from https://www.researchgate.net/publication/292432218_A_Step-By-Step_Guide_To_Qualitative_Data_Analy sis

Popper, M. (2000). Installing Mechanisms And Instilling Values: The Role Of Leaders In Organisational 
Learning. The Learning Organization, 7(3), 135-145. https://doi.org/10.1108/09696470010335854

Randolph, J. (2009). A Guide To Writing A Dissertation Literature Review. Practical Assessment Research and Evaluation, 14(13), 1-13. Retrieved from https://pareonline.net/getvn.asp?v=14\&n=13.

Richie, J., Lewis, J., \& Elam, G. (2013). Designing And Selecting Samples. In: Maruster, L. and Gisenberg, M. Qualitative Research Methods. London. Sage. Retrieved from

https://books.google.jo/books?id=KdneDQAAQBAJ\&printsec=frontcover\&source=gbs_ge_summary_r\&ca $\mathrm{d}=0 \# \mathrm{v}=$ onepage $\& \mathrm{q} \& \mathrm{f}=\mathrm{false}$

Rossi, P., Lipsay, M., \& Freeman, H. (2003). Evaluation: A Systematic Approach (7th ed.). USA.Sage Publications Inc.

Rousseau, D., \& Cooke, R. (1988). Behavioral Norms And Expectations: A Quantitative Approach To The Assessment Of Organizational Culture. Sage Journals. Group \& Organization Studies, 13(3), 245-273. Issue published: September 1, 1988. https://doi.org/10.1177/105960118801300302

Rowe, C. (1996). Evaluating Management Training And Development: Revisiting The Basic Issues. Industrial and Commercial Training, 28(4), 17-23. https://doi.org/10.1108/00197859610120083

Saunders, M., Lewis, P., \& Thornhill, A. (2007). Research Methods For Business Students (4th ed.). England.Pearson Education Limited.

Sessa, V. I. (2018). How Multiteam Systems Learn.

Simonin, B. L. (2017). N-Loop Learning: Part II - An Empirical Investigation. Learning Organisation, 24(4), 202-214. https://doi.org/10.1108/TLO-12-2016-0100

Sisaye, S., \& Birnberg, J. G. (2010). Organisational Development And Transformational Learning Approaches In Process Innovations: A Review Of The Implications To The Management Accounting Literature. Review of Accounting and Finance, 9(4), 337-362. https://doi.org/10.1108/14757701011094562

Yin, K. R. (2009). Case Study Research: Design and Methods. Sage Publication Inc. (4th Ed.) USA. Retrieved from https://books.google.jo/books?id=FzawIAdilHkC 
Appendix 1. Training Report

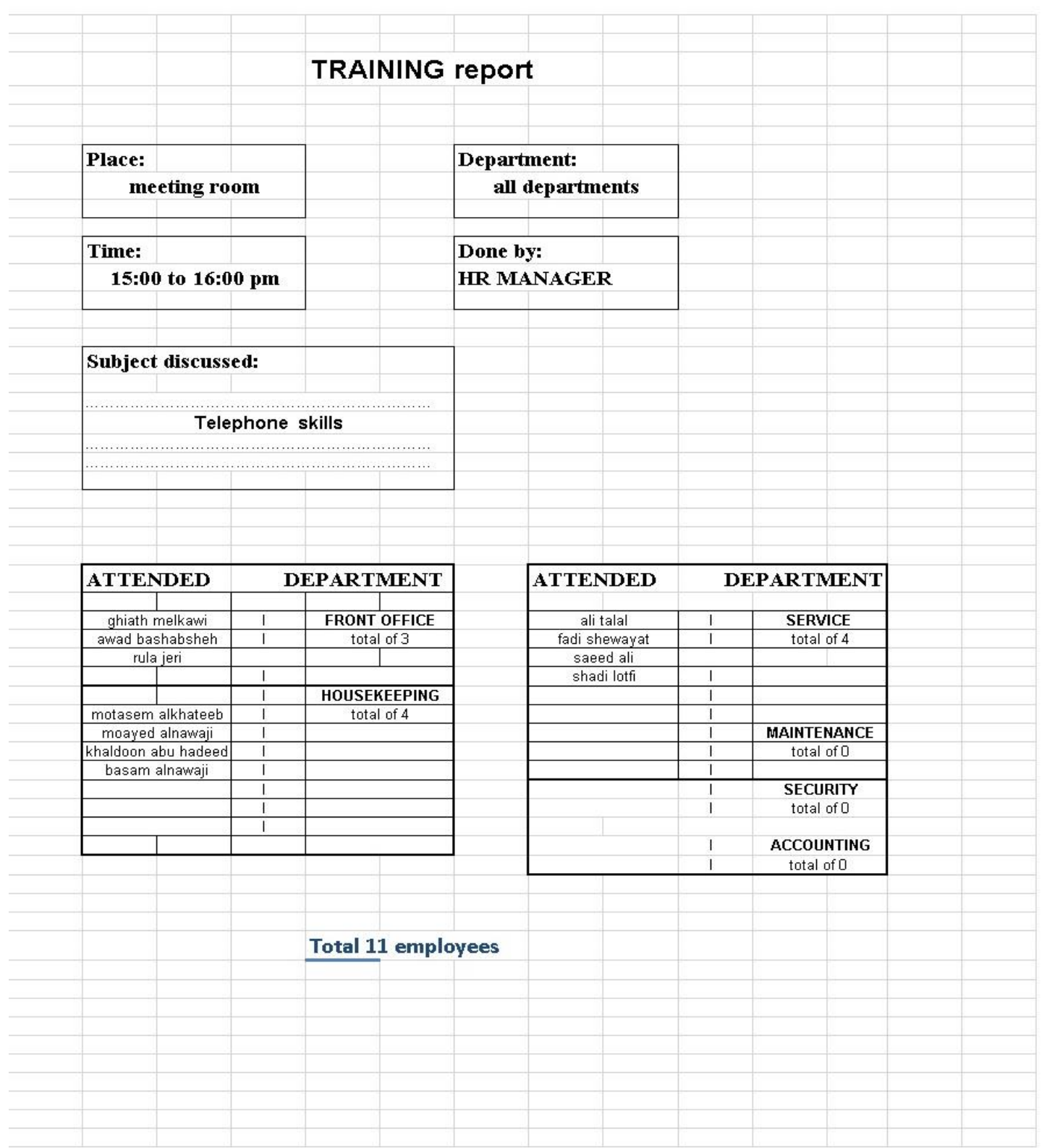




\section{Appendix 2. The Training program}

\begin{tabular}{|c|c|c|}
\hline Objectives & Objectives & Objectives \\
\hline $\begin{array}{l}\text { In this sesston wil be reviewing: } \\
\text { a Professional telephone service to both } \\
\text { internal and external callers } \\
\text { a Provide a suitable greeting and fareweil to } \\
\text { callers }\end{array}$ & $\begin{array}{l}\text { In this session wil be reviewing } \\
\text { a Professional telephone service to both } \\
\text { internal and extemal callers } \\
\text { a Provide a suitable greeting and farewell to } \\
\text { callers }\end{array}$ & $\begin{array}{l}\text { - Use the telephone effectively } \\
\text { - Transfer andior place a call on hold } \\
\text { - Take a written message }\end{array}$ \\
\hline Objectives & Prior to Answering the Telephone & Prior to Answening the Telephone \\
\hline $\begin{array}{l}\text { - Use the telephone effectively } \\
\text { a Transfer andior place a call on hold } \\
\text { - Take a writton message }\end{array}$ & $\begin{array}{l}\text { ABe prepared } \\
\text { - pen and paper } \\
\text { - telephone extension } \\
\text { Ist } \\
\text { a Avoid choming, galing, } \\
\text { drinking or smoking } \\
\text { aUse comrect posture }\end{array}$ & $\begin{array}{l}\text { a Be prepared } \\
\text { - pen and paper } \\
\text { - telephone exterision } \\
\text { list } \\
\text { a Avaid chewing, eating. } \\
\text { dinking or smoking } \\
\text { a Usa correct posture }\end{array}$ \\
\hline
\end{tabular}

\begin{tabular}{|c|c|c|}
\hline $\begin{array}{c}\text { Answer the call with a smile on } \\
\text { your facel }\end{array}$ & $\begin{array}{c}\text { Ansiver the call with a smile on } \\
\text { your facel }\end{array}$ & Answering the Telephone \\
\hline & & $\begin{array}{l}\text { Focus on the caller a } \\
\text { Answer within threo rings a } \\
\text { Communication Center: a }\end{array}$ \\
\hline Transferring a Call & Answering the Telephone & Answering the Telephone \\
\hline $\begin{array}{l}\text { ase guest's name (parsonaliza the call) } \\
\text { a Contim understanding of the reason for } \\
\text { the cal } \\
\text { a Ask a closed question } \\
\text { for confirmation. }\end{array}$ & 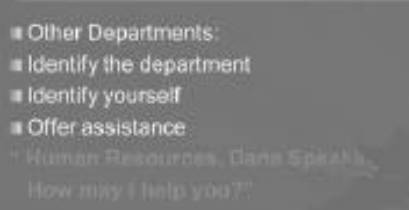 & 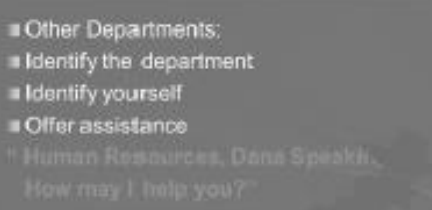 \\
\hline
\end{tabular}

\begin{tabular}{|c|c|c|}
\hline $\begin{array}{l}\text { Transferring or } \\
\text { Placing Calls on Hold }\end{array}$ & Taking Messages & Ending the Call \\
\hline $\begin{array}{l}\text { Explain delays: Nax time for person on } \\
\text { hold is I } \\
\text { atet the caller know } \\
\text { - why you sre } \\
\text { transerring tre cal } \\
\text { - who they ars } \\
\text { beina transfirned to }\end{array}$ & $\begin{array}{l}\text { a Message for } \\
\text { a Name and tille of caller } \\
\text { a Compeny name } \\
\text { a Telephone number } \\
\text { a Time and date of call } \\
\text { a Message }\end{array}$ & $\begin{array}{l}\text { End the conversation on a positive note } \\
\text { Thank the caller } \\
\text { Use the caller's name }\end{array}$ \\
\hline
\end{tabular}


Appendix 3. Time Line

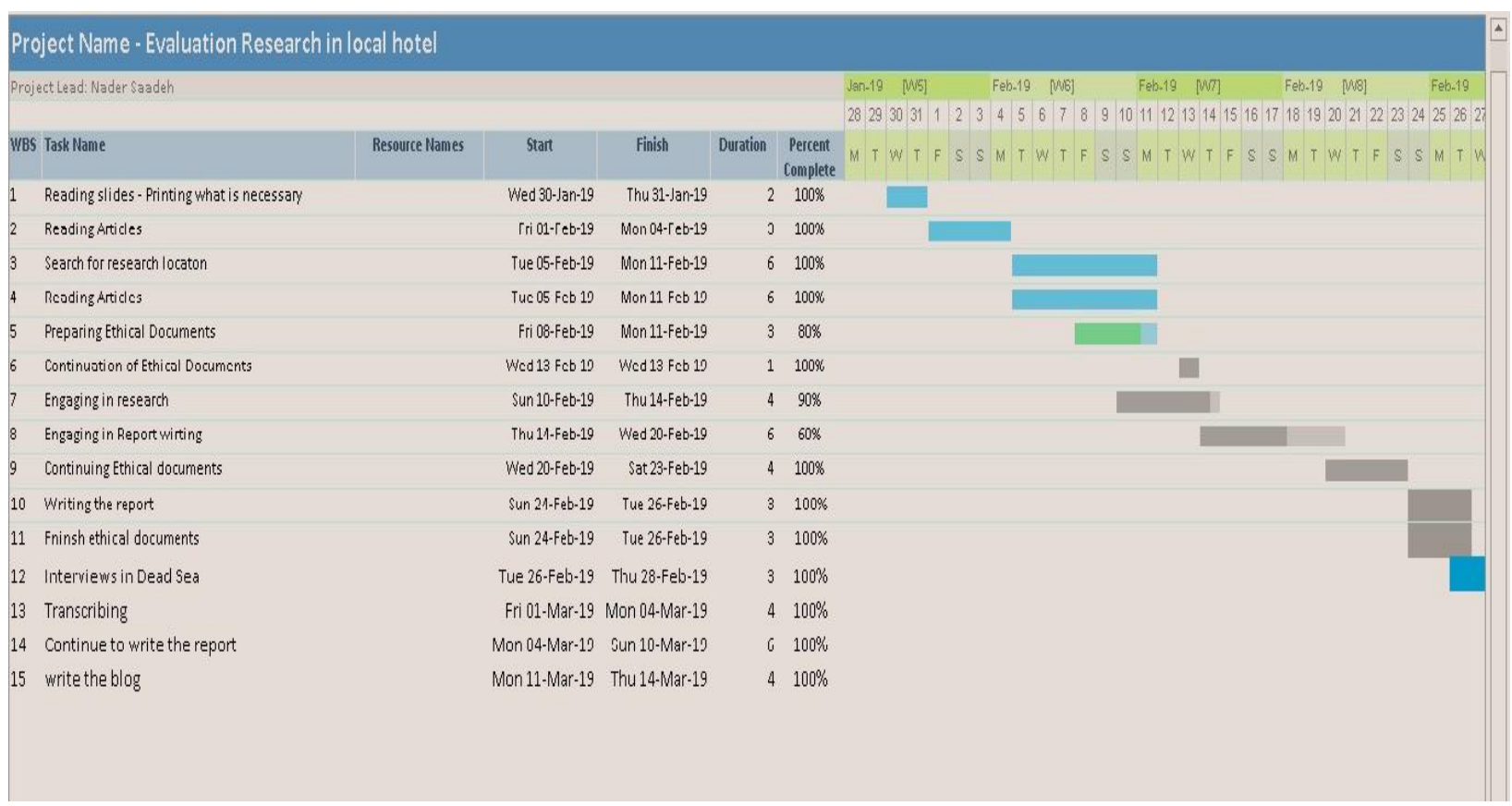

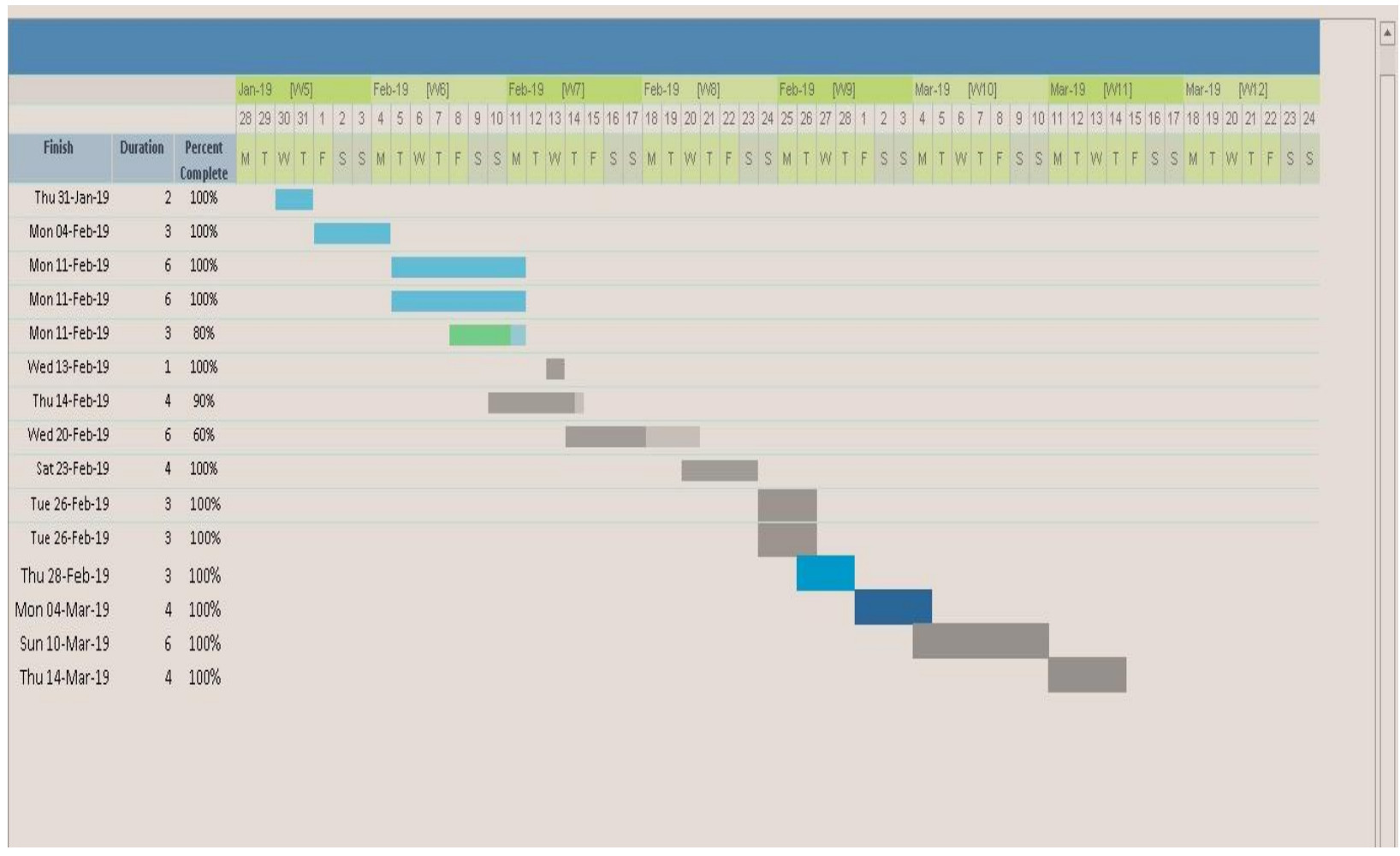




\section{Appendix 4. Transcribed manuscripts}

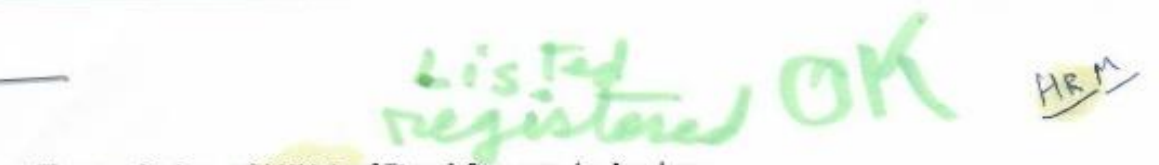

Transcription of HRM of Dead Sea spa in Jordan

Thank you for your cooperation...

Date: Tuesday, February 26, 2019

Q1: You conducted this training program for the telephone skills...

Al yes I am

Q2: How did they acquire know knowledge and skills from this program as you see it as you interpret it?

A2: ok it is a good question actually they had new knowledge after this training course as telephone skills because we are a four star hotel and for the staff developing the staff to answer the staff the phones... developing

Q3: So did you see any impact?

A3: yes it was very good impact and mostly at the front office department because they are mainly the ones they are dealing with telephone of those departments in our hotel.

Q4: so you mean they used all of the procedures that you trained them on...

A4: as front office yes they used all of the procedures what I have trained them to do in the last month in the telephone skills, Telephone procedures: taking messages answering the phone transferring the calls a lot of things

Q5: how did you measure this or by observation?

A5: after the training I was observing those they were starting this course and they were evaluated, and that is why we had the impact on them.

Q6: with evaluation?

Yes with evaluation

How did you do the evaluation?

A6: actually I was calling for example to make sure that they are answering the phone and transferring... yes

Q7: Did you see this happening until now and today is the $25^{\text {th }}$ of February 
A7: uptofnow yes up to now yes... so you are following... yes

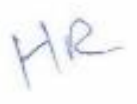

Q8: Only in this department or in other departments?

A8: in this department mainly (front office) but other departments they need some time to clear it with them.

Q9: how is the program has an impact on the performance of the hotel? And to what extent?

A9: it was good specially at the front office and they improved on it and other departments if I give percentage it is about $80 \%$ they were from this impact from this program.

Q10: so they ... $80 \%$ improvement? Yes improvement.

By your observation ( food and beverage and housekeeping)

Q11: how much time this program in your opinion or in your interpretation to be most effective? Now this program was one hour for each day for two days the $25^{\mathrm{t}}$ and the $26^{\text {th }}$ of January. In your interpretation how would you see it will be more effective if you do it another lime?

A11: if we do it another time we might put some other points to train them and we need more time for it. But as it is for this program 1 believe it is enough the timing for this program it is enough.

Q12: would you add other things in the program like... in literature - empirical literature which means out of experiment like what we see in other institutions or other organisations other hotels government institutions and others ... they use different things like in social interaction in emotion work and in cultural diversity and this would have more impact and it will be as I see out of the findings more effective for the performance of the employees, would you add some of these. things?

A 12: actually, yes I would it might need more time from the program that we are conducting but as training programs it is nonstop and there are always new thingse to be added and simple thing like telephone skills to the voice it is important also and this the simple thing $\mathrm{I}$ am thinking about. $\mathrm{Ok}$

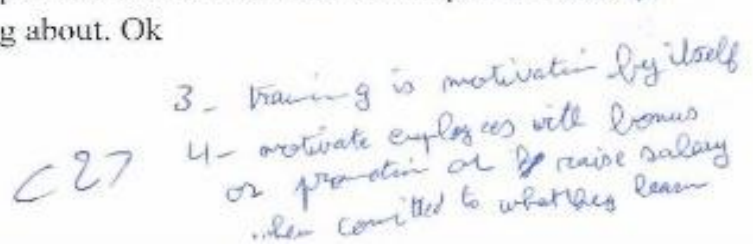


Q13: So you keep on doing programs, quarterly?

A 13: another two months we do it... not only in telephone skills? No no there are other training courses.

Q14: is the program content enough in your interpretation and why?

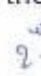

2

$\gamma^{2}$

A 14: the program I think it is enough because it focus on certain points and for those certain points they are enough for our staff.

Q15: given this program how would you think of a better one conducted in improving performance of conducting telephone calls? or maybe other that telephone calls? Iow would you think of a better one that will improve the performance of the employees that will reflect on the organisation or the hotel?

A 15: there a lot of programs that we can do it like in service how we deal with guest, hospitality, measurements there a lot actually in our field it depends on serving the guest there are a lot of things that we can add to that will improve our

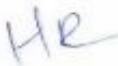
staff... ok in telephone calls? Yes we can do actually in telephone calls like we extend the points we are conducting as I mentioned before there are social things there are tune voice even body language might reflect on the way how you answer the phone ... what about cultural diversity? Diverse of culture too... even also evaluation you do it by observation but you can do it in another way also? It might be like through the department head writing a letter but I believe by myself like to the staff focusing or how these calls are effecting them by watching them I see how there are doing it. But there are procedures in evaluation but myself I think it is much better to see what they are doing on the field actually.

Q16: would you relate any improvement in their performance to motivation?

A 16: of course training is motivation... Not only training? Training and the findings of your training would you connect this to some kind of motivation like they ... what kind of motivation A: sure they motivate and they like it, maybe it is personal motivation maybe it is

You mean the training itself motivation not only you motivate them with bonuses

$$
\begin{aligned}
& \text { dwerwh } \\
& 2 \text { encos }
\end{aligned}
$$

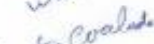

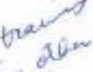
os

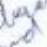
of $\operatorname{lol}_{m} x^{2}$

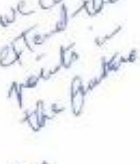
W

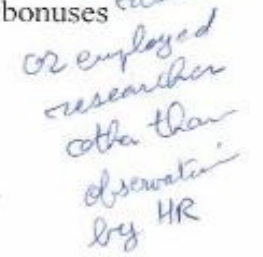




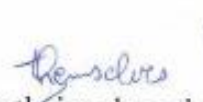

This is actually when conducting the program and they improve their selves there might be raising the position (New one) they might get extra salary or something like that but itself it is motivation.

Q17: finally is there anything connected to telephone skills which have not been discussed and you would like to bring it up?

A17 as I mentioned before yes there are a lot of things and training is not stoppable and there a lot of points we can discuss and we can see it.

Thank you very much

You are welcome indeed
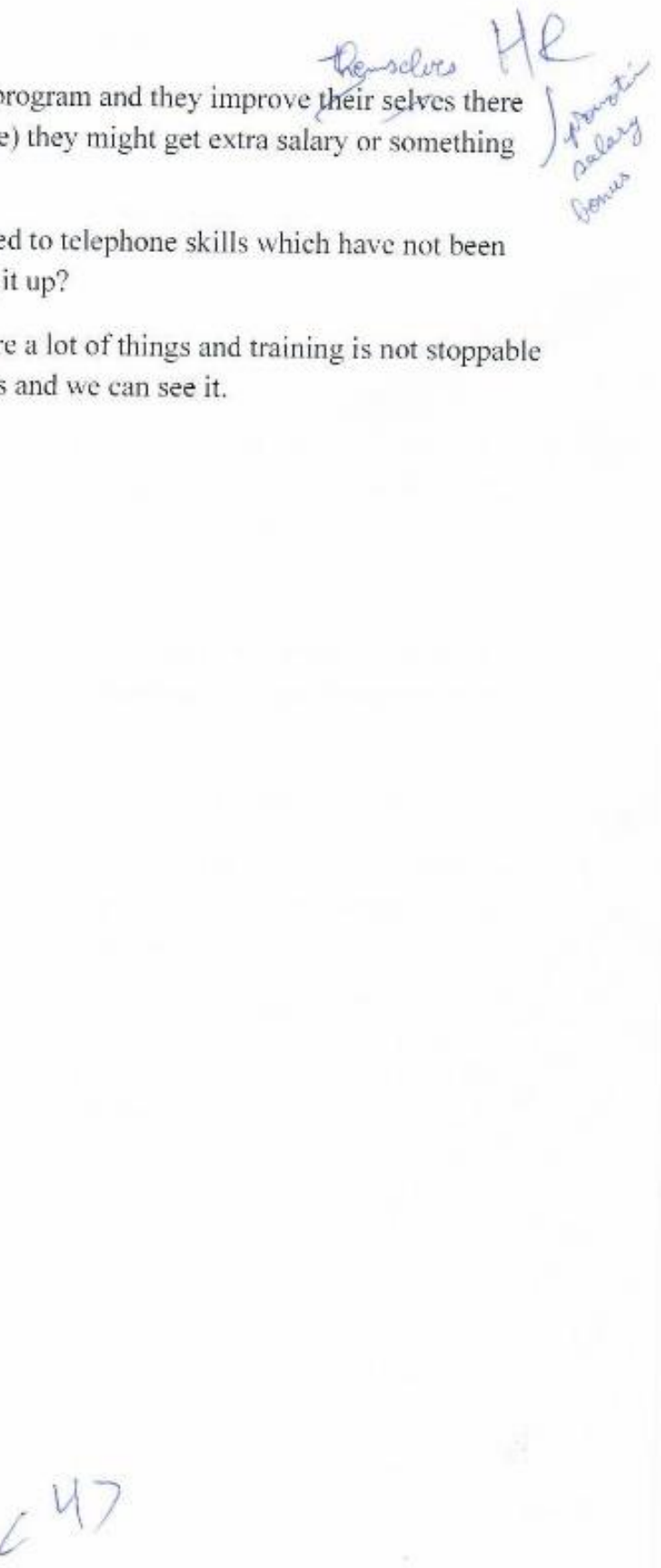


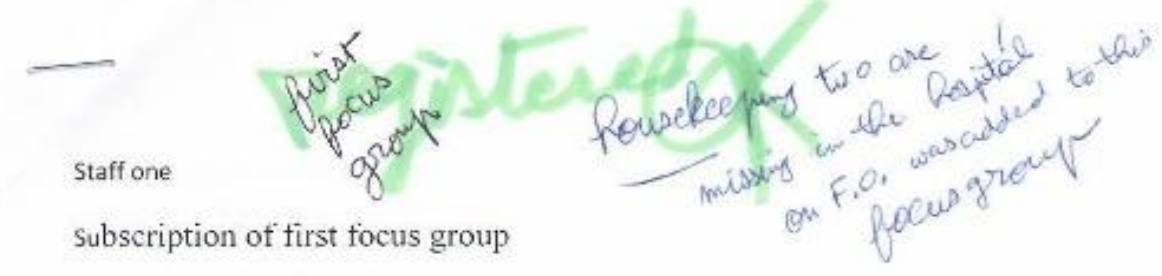

This group was with housekeeping. Two of them off, (going to the hospital, as one employee was sick and the other one was with him).

So the group consisted of two housckecping and one front employee was added to the group. So this focus group consisted of two housekeeping employees and one front desk employee.

$$
\text { cis }
$$

$$
\text { If pere }
$$

The questions were addressed in Arabic and the researcher translated the subscription to English.

Q1 how did you acquire new knowledge and new skills from this program?

A1: now the skill of connection is very important in our work with the guest and we acquired from this program a lot in the knowledge of connecting with the guest and sales and the problems we encounter in a complete way What knowledge?

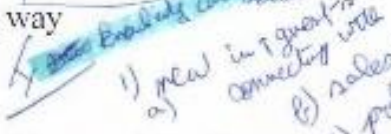

Ghayth: The acquired knowledge: the guest remembers his experience here as memory so let it be good

Mo3tasem: I acquired from this that I can reach to the guest and connect with him or her in letting him to know with whom he is speaking which hotel the guest is connecting with and who is the person who is speaking with the guest and I learned how would I relate this to the guest

Was it added knowledge to you? Or you knew about this before?

Yes it was new for me

Before I used to answer in my name now $I$ answer in the name of the hotel and to respond gently in saying good evening good morning and so on and telling him about which hotel he is speaking with and which department he is trying to reach

Mo2ayad: the acquired skill how to speak with the customer, the first one the guest is speaking with is the call agrent so he takes the first impression out of this call and accordingly he may book in this hotel or no. so the way the employee is speaking

$$
<17
$$


is it good gentle that reflect good impression or no is important and this what I learned in this program

So booking could be done through you? Right?

Sure if the customer was pleased from the call sure he will book in the hotel come to you.

You are talking as front office right? How is it as housekeeping??

If the customer was in the hotel accommodating and I answered him with gentle way sure he will be pleased and come back to the hotel.

Q2: in this case study that I am conducting it is an evaluating study does this evaluating procedure gives you motive to better work in your job peivits to comside

Yes sure because your evaluation will modify my way of serving according to your direction

So if the HR did this evaluation is it motivation to you Sure

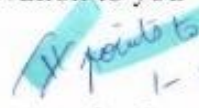

How this program would have an impact on each of your performance?

And to what extent
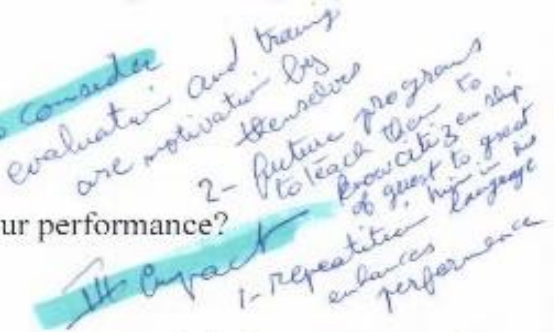

Mo2ayad: we had skills from before but this program we repeated the information of the skills this was ensuring our past experiences and there was new things ... every program has new things to acquire

Has it any impact? Sure

$\mathrm{OK}$ if the program was repeated twice a year or four times a year what do you think about performance would it be better?

Sure if it was repeated more the performance would be better because every time you acquire new thing... Q: or even the motivation

Yes this motivates us even if the same programs repeated. So it may add new content but we I repeat the old ones.
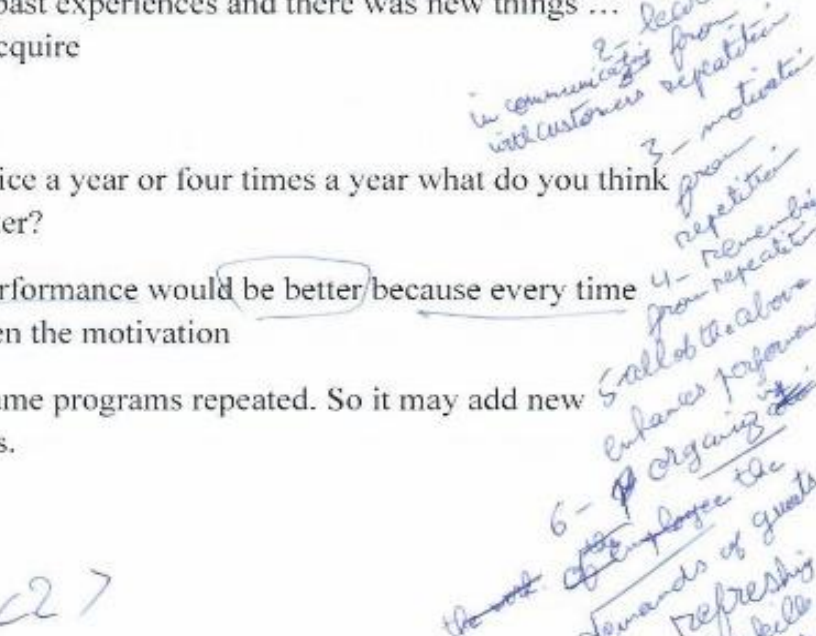

nk
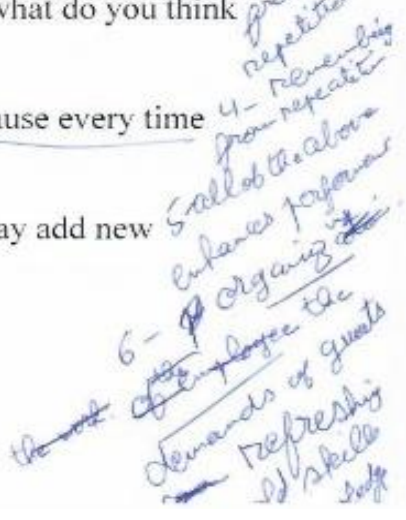


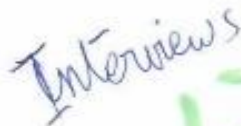

Front office the rest of the two employees

Welcoming and briefing

Rula and awad

Q1: How did you acquire new knowledge and new skills from this program?

Rula I learned how to answer the guest on the telephone and how we can improve our hotel for the guest and how we can make new sales for guests

Q so was it new knowledge?

Yes more knowledge and skills

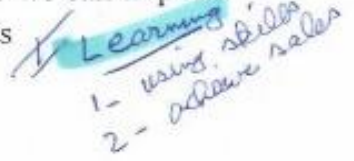

We could not know how to hold the answer of the guest before on the operator and meMohamed told us to hold for 60 seconds and how we can transfer and talk to another guest and how we can hold three calls at the same time 2-seiles

It was now knowledge and skills

2

Awad: what I benefit is the to hold three guests the same time ie to put them on hold and how to transfer every call to a department by itself 2,2 pille

Q2 how this program impact the performance and to what extent?

Awad: my performance it added a lot to me as for the department it added too

I had knowledge from before about how the perforryance must be from university and from my experiences from other hotel

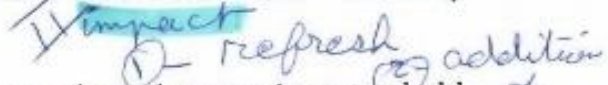

Rula: improve our knowledge and improve our experience because I can not hold three calls at the same tie and Mr. Mohammad says to us how to hold the guest for Emoulfelge example if we talk to other guest we excuse him and we hold for 30 seconds and seills we say thank you for holding to go the $3^{\text {re }}$ call and we transfer and we go to the $1^{\text {st }}$ and finish it and so on

So there wasimpact positive

Yes<smiles>CCOCCOCCOCCOCCOCCOCC</smiles>

Q3 how much time for the program to be effective? To reach to the goals 

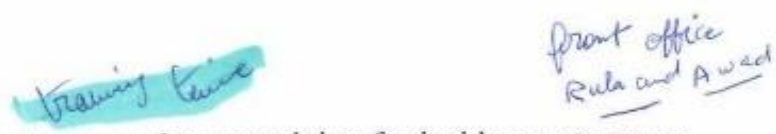

We were trained for outside guests we need more training for inside guests so we need more training on this internal and we need more practice

Do you think repeating this program with more aspects what do you think?

Is it better on performance?

Of course more experience

In what way

As HR says

Do you have more ideas

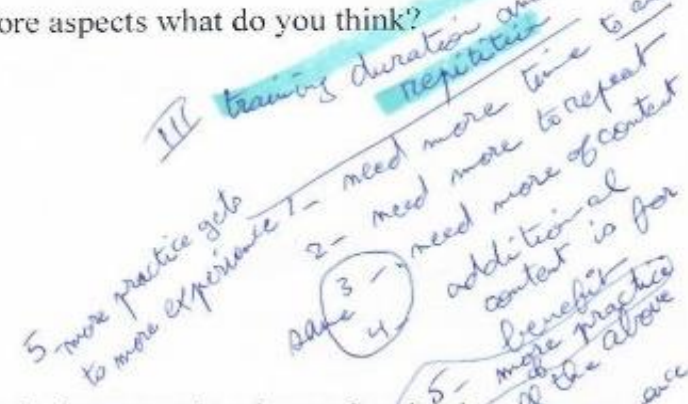

Maybe some hotels collect all the employees in the same chamber and make the of presentation to all of us from different departments

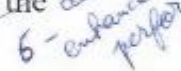

Awad: the program was good as for the internal guest but one hour is not enough because you have to ask questions and one hour is not enough and we need more time to get the benefit through questions

What about repeat 6 times in a year what is the impact on department performance?

It get more benefit especially for new employees this will raise performance and will give it value

What about the content was it enough

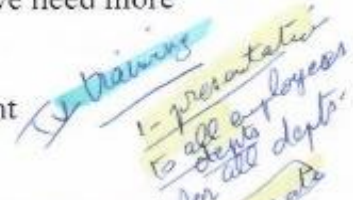

Yes

Why

/ Because it gave you the needed skills that you have to acquire to deal with guests

on the phone and this through how you deal with more than one call at the same

time and the mechanism how to transfer the calls

Have you heard about cultural diversity training programs?

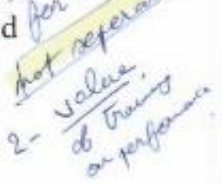

Awad: yes and need training programs (cmore) 
In repeating there is rising in performance is that true

Sure it is true

Mo3tasem: if the program was repeated 4 times so it will repeat the piece of information more than one time this enables me not to forget the information and this enables me to acquire new thing too and the effect of this program on me I learned how to organize the calls of the guests to know what were their demands how many guest called me .... actually the program taught me how to organize all this. The impact was in teaching me how to organize my work what were all the demands of the customers what was the message from them and their demands and how I organized those demands and how I better served them

This meant to you that in your job description as housekecping not only in cleaning the rooms but also in how to communicate with the customers in a better way or professional way

Sure $7: 16 \mathrm{~m}$

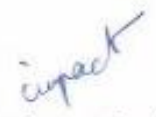

Ghayth: the program refreshed our information in front office and added how we deal with the guest from time to time it is good to conduct this program.

Q4: how much time this program, is effective and gets to its goals more? Ie this program one hour each day is this enough?

Ghayth: it is enough as such but to have once a month one hour will be good

This will review our memory so repeat his is good

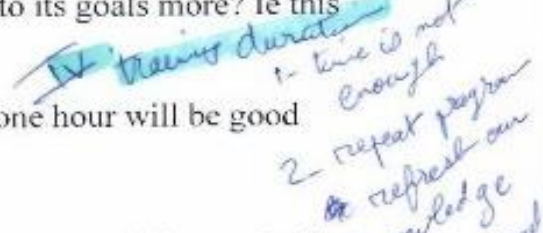

$2^{\text {nd }}$ person: I am with this repetition that is if four times a year will be good this $\&$ will refresh our old knowledge and if new ones are added this will be good

Mozayad: need more time than this

Q5: what about the content was enough and why?

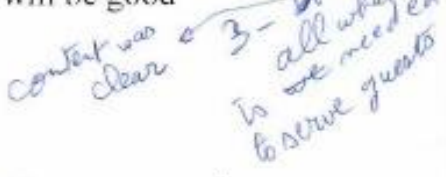

Mo2yad: it was enough because it took all aspects that is related to guests or the past training

Mo3tasem: yes enough because through this program I can give to the guest everything that he asks for 
Food and beverage department 4 employees.

Shadi sa3id ali fadi

Welcoming and brief

Q1: how would you see that you acquire knowledge and skills?

Shadi: the important thing that I talk to the gucst without I see him I listen to him then to know what to answer him and to let him know the department that he rang to because it is important for the guest to know where did he ring so you welcome him then tell the department that rang to

Is it new knowledge

$$
\text { Re wathe aning to }
$$

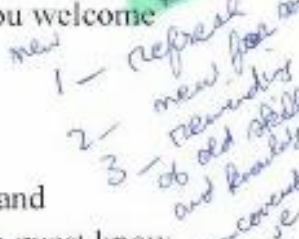

For me it was refresh for my colleagues some was new for me refresh and reminding it was necessary for us to remind us with this thing to let the guest know where he called which department... and I try to know what he wants and try to of r help him and if 1 can not 1 take the piece of information and transfer it to the department that is specialized in this service

Sa3id: yes it is new hecause this is the first hotel that I worked with and you improve yourself how to start the conversation with the customer with the correct word good morning my name is ... and so on and the new thing was the wording that they taught us with how to talk with the guest in a gentle way as he pleases

Ali: this was reminding and refreshing and this is very good and to know how to talk to the guest and to make the guest know where did he ring

Fadiright as shadi wold us when the gust ring we take the time that he rang then we take what service he needed then then we try to help him without we upset him

So if the guest rang in $f$ and $b$ and he wanted something from other department I take the piece of information from him and then we communicale it with other department and take what he asked for and write down the room number and then serve him the way he asked for

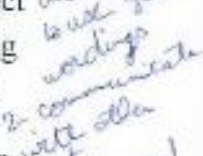
280 os 
Shadi: it was refreshing we used to forget room number now we are concerned about taking full information

Q2: how was it as impact on performance?

Shadi: it was good now if some new employee come we train him according to standard and the standard is written in papers and we tell him all the procedures

The program was all in documents.

ladi: before when somcone rings we answer room service and if ask for something we tell him call this department but now we answer in a professional way and we try to handle all what the guest want ourselves

Was there an impact on performance?

Yes and also the return now is better now the guest if he expericncengentle answers

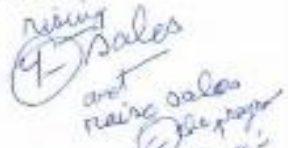
from the employees and he orders food now you offer beverage if he does not want food and this is we were trained on this to make upsale

And this was good for upsales from this programs we benefit to raise sales

Q3: was the time enough and why?

Ali: for one day no for 2 days it was good

Sa3id what if the HR repeat the program ? yes it will be beneficial

Q4: What about the content Fadi

Ali: it was excellent all the points were excellende

Shadi: all the points were important

And now we want to add more things in future programs that emerges from the workplace and we arrange this with HR dept.

Q5: if you want to add something on this program what will be? repeatition

Fadi: peputation of programs

Ali: to add a piece of paper that show all numbers of departments
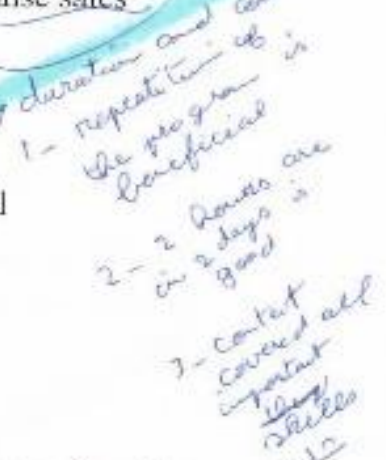

Q

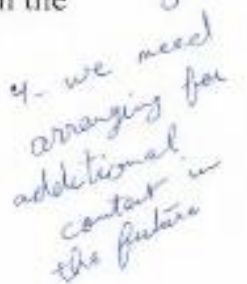


Sa3id: nothing

Shadi: sometime we take orders from the guest related to other depts.

So we want the cooperation of other depts, With us to serve the customer

Fadi: put the numbers of the depts. In the room to solve this problem

Have you heard about diverse culture programs?

How is if we add this to programs? And there is emotion work"?

Shadi: when a guest is upset we have to answer seriously and in a gentle way and answer as one body one team and respond to his demand

Wc want programs that ensure the one team spirit if a guest ask any thing then we cooperate to serve the guest

The program itself is it motivation to you? burtpor

Fadi: sure it gives you motive that you do not fear talking to guests it gives you trust to talk to customers so repetitions are enhaneing to performance

We serve customers as one team and depls. Cooperate to serve him and not to say this is now my job

Q6: Finally what point we would diseuss and discussed?

Shadi: it covered everything dealing with how to deal with the guest on the phone and how tu serve him but there are other things for example to take the program from different programs to leam how to in between depls.

Sa3id it covered everything fored ede of

Fadi: to be as one team not to say to the guest no

Thank yosu

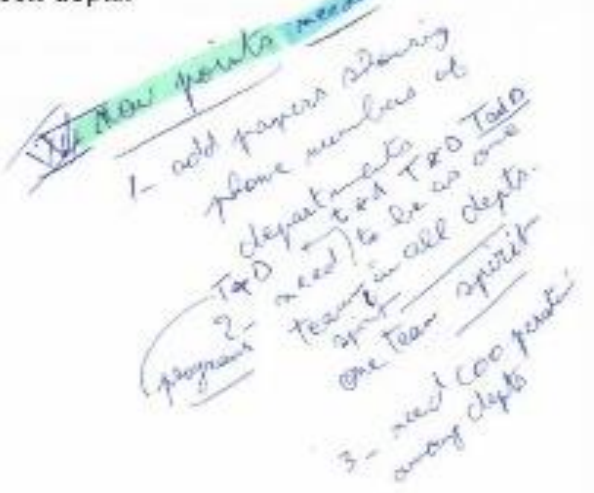




\section{Appendix 5. Schedule}

- The welcome.

- An overview of the topic (reviewing the program and explaining the purpose of the evaluation process).

- Assurance of confidentiality.

- The questions:

- How did you acquire new knowledge and skills from this program?

- How is the program has an impact on your performance? To what extent?

- How much time for this program to be most effective?

- Is the program's content enough? Why?

- Given this program, how would you think of a better one to be conducted, on improving the performance while doing telephone calls?

- Finally, is there anything connected to telephone skills which have not been discussed and you would like to bring it up?

Background information (gender, age, etc.).

\section{Copyrights}

Copyright for this article is retained by the author(s), with first publication rights granted to the journal.

This is an open-access article distributed under the terms and conditions of the Creative Commons Attribution license (http://creativecommons.org/licenses/by/4.0/). 